\title{
O Ensino de Português Língua Estrangeira como Diplomacia Cultural: atividades de cultura brasileira
}

\author{
Davi Borges de ALBUQUERQUE*
}

\footnotetext{
* Doutor em Linguística pela Universidade de Brasília (UnB). Membro do Núcleo de Estudos de Ecolinguística e Imaginário (NELIM) da Universidade Federal de Goiás (UFG). Contato: albuquerque07@gmail.com.
}

\section{Resumo:}

No presente artigo, ampliamos a discussão sobre a concepção do professor de Português Língua Estrangeira (PLE) como um diplomata cultural, e discorremos sobre os aspectos teórico-metodológicos da prática docente do professor de língua estrangeira, apontando os conceitos de abordagem, métodos e técnicas. Ainda, procuramos descrever uma proposta de atividade de cultura brasileira que esteja em acordo com as teorias por nós discutidas. Logo, o objetivo deste texto é duplo: primeiro, defender a ideia do professor de língua estrangeira como um diplomata cultural; segundo, apresentar nossa proposta de atividade para ilustrar os pressupostos que seguimos. Assim, após a introdução, discutimos a concepção de professor de PLE e a diplomacia cultural; depois, apresentamos as teorias do professorpesquisador, da pesquisa-ação e das metodologias ativas, bem como as noções de abordagem, método e técnicas; em seguida, descrevemos uma atividade que utilizamos em nosso planejamento, chamada de 'temas brasileiros', e algumas sugestões para desenvolvê-la. Em nossas considerações finais, além de retomarmos algumas ideias centrais, apontamos a importância do apoio, das iniciativas particulares e das públicas, ao professor de PLE.

\section{Palavras-chave:}

Português Língua Estrangeira (PLE). Diplomacia Cultural. Cultura brasileira.

Signum: Estudos da Linguagem, Londrina, v. 23, n. 1, p. 133-150, abr. 2020 


\section{O Ensino de Português Língua Estrangeira como Diplomacia Cultural: atividades de cultura brasileira}

Davi Borges de Albuquerque

\section{INTRODUÇÃO}

A língua portuguesa é a sexta mais falada do mundo, contando com cerca de 200 milhões de falantes (CARVALHO; LUCCHESI, 2016), sendo a língua oficial do Brasil e de mais sete países, a saber: Portugal, Angola, Guiné Bissau, São Tomé e Príncipe, Cabo Verde, Moçambique e Timor-Leste, que formam a Comunidade dos Países de Língua Portuguesa (CPLP).

Com as crises econômica e financeira no início do século XXI, o Brasil se destacou no cenário internacional, o que despertou maior interesse pela aprendizagem da língua portuguesa como língua estrangeira por cidadãos de diversos países, além de sua influência nas relações internacionais, principalmente no MERCOSUL e no BRICS. Ademais, a globalização, a internet, os smartphones, os softwares e os aplicativos, os processos de fusão de línguas e de expansão das relações, ou seja, a cibercultura, alteraram todo o processo de ensino e aprendizagem de línguas estrangeiras (LEFFA, 2016), bem como a procura e as demandas das línguas. Com tudo isso, o português passou a ser ainda mais valorizado internacionalmente e o Brasil também se destacou.

Para ilustrar o aumento dessa demanda, mencionamos alguns dados e iniciativas: Castro Neto (2013, p. 18) corrobora tal afirmativa informando que a procura pelo exame do Certificado de Proficiência em Língua Portuguesa para Estrangeiros (Celpe-Bras) do Ministério da Educação (MEC) "saltou de 127 inscritos na primeira edição do exame em 1997 para mais de 9.000 em 2012”; o Ministério de Relações Exteriores (MRE) e o Departamento Cultural e Educacional do Itamaraty (DCED) mantêm o 'Programa Leitorado para Instituição Estrangeira', o qual, anualmente, envia entre 10 a 20 professores para ensinar língua portuguesa, literatura brasileira e cultura para diferentes Instituições de Ensino Superior (IES) estrangeiras; há algumas ações da Rede Brasil Cultural, sob a responsabilidade do MRE.

No nível acadêmico, os exemplos de departamentos, grupos, cursos e projetos de sucesso são bem maiores, entre eles: a Sociedade Internacional de Português Língua Estrangeira (SIPLE), que possui um periódico e um congresso regulares que contribuem bastante para os profissionais atuantes no ensino de Português Língua Estrangeira (doravante PLE); o Centro de Línguas e Interculturalidade (CELIN), da Universidade Federal do Paraná (UFPR), que possui os projetos 'Multiletramento no contexto de ensino de PLE', 'Produção e avaliação de materiais didáticos para ensino de PLE', 'Estudos e práticas relacionados ao exame de proficiência Celpe-Bras' e 'Desenvolvimento de recursos para ensino-aprendizagem de PLE na modalidade a distância'; as experiências positivas de ensino de PLE em imersão, na Universidade Federal de Uberlândia, conforme relatadas por Yamamoto (2014) e Chagas (2016); o Núcleo de Ensino e Pesquisa em Português para Estrangeiros (NEPPE), da Universidade de Brasília; e os diversos cursos e projetos em andamento de algumas universidades públicas brasileiras reconhecidas, as quais possuem núcleos específicos para ensino e/ou pesquisa de PLE. ${ }^{1}$

\footnotetext{
Esta lista não é exaustiva e receamos termos sido injustos e deixado de mencionar outras grandes iniciativas já feitas ou em andamento. Além dos departamentos, cursos, projetos e afins, há também, nas duas últimas décadas, um crescimento significativo na pesquisa e nas publicações de artigos científicos, dissertações de mestrados, teses de doutorado e comunicações apresentadas em eventos da área.
} 
Contudo, não há somente aspectos positivos nessa expansão da língua portuguesa quando a encaramos sob a perspectiva do ensino de PLE e das políticas linguísticas. Na primeira década do século XXI, Pacheco (2006) e Almeida Filho (2011) destacam que os cursos de formação de professores de PLE, bem como centros de pesquisa e pós-graduação, ainda eram reduzidos e em números ínfimos. A nosso ver, esses números ainda não se modificaram, apesar de não obtermos dados mais recentes. Ademais, até a atualidade, Borges (2015) nos chama a atenção para o fato de que o governo brasileiro não elaborou documento oficial algum sobre o ensino de PLE, e lista as iniciativas oficiais e acadêmicas existentes, enfatizando que a política linguística brasileira em nível internacional é fraca. ${ }^{2}$

É nesse contexto, entre aspectos positivos e negativos, que consideramos fundamental a divulgação das pesquisas, propostas de atividades e relatos de experiência, e é aqui que procuramos inserir e localizar nosso trabalho, trazendo reflexões teóricas para a melhoria da prática do professor de PLE e uma proposta de atividade em concordância com essas reflexões, ou seja, objetivamos contribuir com a área e apoiar os demais colegas na ativa em PLE.

No presente artigo, desenvolvemos a concepção do professor de PLE como um diplomata cultural, expomos alguns aspectos teórico-metodológicos de nossa prática docente e apresentamos uma proposta de atividade, já empregada por nós, que une esses elementos teóricos e práticos por nós adotados, discutidos nas seções seguintes deste texto. Tal atividade tem como objetivo ensinar traços culturais básicos do cotidiano brasileiro e, também, desfazer alguns mitos que o público-alvo estrangeiro possa ter.

Assim, primeiramente, discutimos a concepção do professor de PLE, e de qualquer professor de línguas, como um diplomata cultural; na sequência, apresentamos os pressupostos que guiam nossa prática docente, sendo eles: o professor-pesquisador, a pesquisa-ação e as metodologias ativas, bem como noções de abordagem, método e técnicas; descrevemos, em seguida, nossa proposta de atividade e alguns resultados e ideias para desenvolvê-la. Finalmente, escrevemos nossas considerações finais.

\section{O Professor de Ple como um Diplomata Cultural}

A ideia do professor de línguas, especificamente o professor de PLE, como um diplomata cultural é definida por Moutinho e Almeida Filho (2015) como a atuação do professor que não se limita apenas a ensinar a língua, mas se torna um facilitador, promovendo diferentes espaços de uso da língua-alvo e de sua cultura, em consonância com os interesses dos alunos e com a participação deles. Ademais, o professor, no papel de um diplomata, acaba também por aprender a língua e a cultura de seus alunos para, junto com eles, participar nos diferentes espaços, tornando, assim, a relação professor-aluno e a aprendizagem da língua-alvo um processo positivo, amigável e harmonioso.

Consideramos tal perspectiva importante para a formação e a atuação do professor de PLE; porém, a nosso ver, essa visão deveria ser desenvolvida para os estudos de PLE e Linguística Aplicada e permanece subestimada, mesmo que os professores de língua já pratiquem uma forma de diplomacia cultural, alguns conscientemente, outros sem o saber. ${ }^{3}$

Em relação aos aspectos teóricos, o conceito de 'diplomacia cultural' consiste, atualmente, na prática de cooperações e/ou trocas culturais entre dois países ou um grupo específico de países (ANG; ISAR; MAR,

\footnotetext{
2 Para uma análise da política linguística brasileira, incluindo um histórico e certas críticas, ver Rajagopalan (2013).

${ }^{3}$ Moutinho e Almeida Filho (2015) também fazem um questionário com três professores de PLE sobre suas práticas e conscientização a respeito da diplomacia cultural. O resultado revelou que os três estão conscientes desse papel, porém apenas um deles apresenta soluções para a prática de sala de aula. Assim, reconhecemos que é necessário expandir tal pesquisa a departamentos de universidades que oferecem cursos de PLE, bem como de professores de PLE em atuação nos países lusófonos, ou seja, aumentando o número de professores e questionários aplicados, para verificar o grau de conscientização e em que medida isso afeta suas práticas.
} 
2015). Diferenciando-se das relações culturais, que se dão de maneira natural e orgânica, a diplomacia cultural requer intervenção governamental e ocorre formalmente, por meio de acordos entre os países e seus agentes, os diplomatas culturais (ARDNT, 2006).

Como envolve agentes específicos - os diplomatas culturais (no nosso caso, professores e alunos, entre outros) -, e bens também específicos - a saber, a cultura (em um sentido amplo) -, a diplomacia cultural está inserida e relaciona-se com os conceitos de 'diplomacia pública' e de 'poder suave'.

A diplomacia pública é definida como a comunicação e a aproximação de um país com o público estrangeiro (WANG, 2011). Dessa forma, percebemos facilmente que a diplomacia pública é uma preocupação notória de alguns países, como Estados Unidos, Inglaterra, França, Japão, Coreia do Sul etc., enquanto não é praticada por outros. As maneiras que um país pode entrar em contato com o público exterior são apontadas por Cull (2008) como sendo cinco: pesquisas de opinião, advocacy, diplomacia de intercâmbio, transmissões internacionais e diplomacia cultural. Essas práticas acabam sendo pensadas como estratégias para melhor se comunicar, conhecer e conquistar parcelas do público estrangeiro.

O termo 'poder suave' (soft power) foi criado por Nye (1990) para se referir a uma espécie de cooptação, ou seja, o oposto a imposições ou ordens, geralmente de natureza militar ou econômica. Assim, os indivíduos cooptados, ou conquistados, pelo poder suave passam a fazer por conta própria e de bom grado o que o agente do poder suave quer que eles façam. Por isso, a temática de bens e serviços culturais se encaixa bem aqui. Como exemplos, as indústrias cinematográfica e musical norte-americanas, que acabam por conquistar grandes públicos e ditar modos de pensar, de dizer e de agir. ${ }^{4}$

Segundo os pressupostos teóricos apresentados anteriormente, e com base em Moutinho e Almeida Filho (2015), o professor de PLE é um diplomata cultural porque ele não se limita a ensinar a gramática ou as estruturas linguísticas, mas, além da língua-alvo, o profissional ensina ao aluno aspectos culturais; pratica a interação em situações comunicativas reais; estimula o aluno, ao levar para a sala de aula seus interesses e suas aspirações em relação à língua-alvo; aprende a língua e a cultura locais (quando ensina PLE fora de seu país de origem), criando laços de amizade entre ambas as comunidades, a da lusofonia e a dos alunos.

Esse professor de PLE, no decorrer de seus cursos, deve apontar também as vantagens de se aprender português, apresentando-as nos mais diversos setores, como: economia, mercado financeiro, ramos empresariais, pesquisa e universidades, entre outras, ${ }^{5}$ e que o uso do português pode oferecer várias oportunidades nos países lusófonos, caso o aluno deseje visitar ou residir em um dos países da Comunidade dos Países de Língua Portuguesa (CPLP), destacando-se: Brasil, como um membro do BRICS; Portugal, como um membro da comunidade europeia; Angola e Moçambique, como economias em ascensão, estando entre os cinco melhores países africanos para investimentos; ${ }^{6}$ e Timor-Leste, uma nação nova que busca apoios e cooperações internacionais.

Nesse caso, o professor exerce o papel de diplomata cultural, praticando também a diplomacia pública e o poder suave ao levar ao conhecimento dos alunos os bens e as práticas culturais dos diferentes

\footnotetext{
${ }^{4}$ Além do âmbito da diplomacia, em PLE há, também, uma preocupação com a pragmática e a importância das situações em que algo é enunciado e seus efeitos (ver a publicação seminal de Austin [1975] sobre os atos de fala), existindo, assim, uma vasta bibliografia, principalmente em relação à análise dos livros didáticos (como esses materiais tratam as interações e usos linguísticos reais), propostas de atividades com simulações ou uso de dados linguísticos autênticos (ensinando gírias, expressões idiomáticas, mudanças de significados específicos para algumas situações, entre outros tópicos) e relatos de experiência.

${ }^{5}$ Citamos somente dois exemplos dessas vantagens, retirados de Borges (2015). A primeira consiste no fato de que o português está entre as línguas mais importantes para o Reino Unido nos próximos 20 anos, segundo o relatório Languages for the Future, do British Council. A segunda é o crescimento da demanda no mundo, principalmente em Inglaterra, Espanha e Estados Unidos, do ensino de português como língua de herança, conforme destacam Souza e Barradas (2013), Borges (2015) e Moroni e Gomes (2015).

${ }^{6}$ De acordo com o documento Africa Investment Risk Report 2019 (EXX AFRICA, 2019), os outros três países são Etiópia, Gana e Mauritânia.
} 
países lusófonos, ${ }^{7}$ conquistando-os, assim, e fazendo com que se tornem simpatizantes da língua portuguesa e da cultura dos diferentes países.

Com isso, não queremos apenas adotar um referencial teórico e abstrato a ser utilizado na pesquisa, pois, ao encararmos a prática do professor de PLE como um diplomata cultural, estamos enfatizando a importância e a responsabilidade de nossa prática diante de nós mesmos, de nossos alunos, da instituição em que lecionamos e dos governos envolvidos. Assim, destacamos também a necessidade da formação sólida desse tipo de professor e a relevância dos apoios institucionais (oficiais e acadêmicos) para a continuidade e boa qualidade dessa prática.

\section{A Prática do Professor de PLE: alguns pressupostos}

Antes de falarmos de nossa prática, sentimos necessidade de delimitar algumas teorias e pressupostos que nos guiam e nos quais nos baseamos. Assim, discutiremos os princípios didáticos de nossa prática docente para, em seguida, definirmos a terminologia científica, ou seja, os aspectos teóricos por nós empregados.

Os pressupostos que permeiam nossa prática docente giram em torno das teorias sobre o professorpesquisador, a pesquisa-ação e as metodologias ativas. Assim, na primeira vertente, consideramos importante a boa formação e o aprofundamento teórico por parte do aluno/professor, por meio de pesquisa, ensinando, praticando e esclarecendo o aluno sobre o que é e como se faz a pesquisa científica, porém sem perder de vista o conhecimento e os avanços da didática (SOARES, 1998; ANDRÉ, 2001), ou seja, procuramos sempre buscar um equilíbrio entre a pesquisa e o ensino, para ensinar alunos capacitados a teoria e a prática em língua portuguesa, de acordo com as necessidades da turma, que é o público-alvo.

Já a pesquisa-ação tem se mostrado eficaz nos três pilares do Ensino Superior - ensino, pesquisa e extensão -, pois faz com que os conhecimentos e as práticas do professor sejam pautados pela necessidade da comunidade, ou de um grupo da comunidade, que deseja a transformação social (FRANCO, 2005); assim, devemos balancear teoria e prática entre o universal e o particular, pensando em estudos de caso da comunidade e no perfil dos alunos (ensino), realizar investigações na e para a comunidade (pesquisa), e divulgar resultados e contribuições de nossas práticas e pesquisas junto à comunidade (extensão) (TRIPP, 2005). Desse modo, a pesquisa-ação está em consonância com o ensino de PLE para um público-alvo de alta escolaridade, bem como para os cursos oferecidos pelas diferentes universidades. Caso o público-alvo e a instituição sejam distintos dos citados (voltados para a academia), cabe ao professor adaptar sua prática com base na pesquisaação, que também se prova eficaz, principalmente com toda a preocupação com a teoria e as práticas voltadas para a comunidade local. Além disso, a pesquisa-ação, com esse interesse na comunidade, está em conformidade com os pressupostos da diplomacia cultural.

Nosso interesse principal nas metodologias ativas é o ensino por investigação (CARVALHO, 2013; CASTELLAR, 2016), pois trabalhamos os conceitos e a terminologia científica da Linguística na prática, ensinando o aluno a pesquisar, a buscar dados, a selecionar uma metodologia, a tecer os resultados e, após aprenderem os aspectos teóricos por meio de uma reflexão de suas práticas, que possam adaptar o que foi ensinado em sala de aula para o seu cotidiano. ${ }^{8}$

\footnotetext{
${ }^{7}$ A maioria dos livros didáticos existentes já apresenta um bom tratamento cultural de temas brasileiros e portugueses, porém os demais países lusófonos ainda carecem desse tipo de obra. Contudo, isso não impede que o professor elabore seu próprio material e atividades que abordem a riqueza cultural dos países/comunidades lusófonas da África e da Ásia.

${ }^{8}$ Recentemente, estão sendo conduzidas algumas investigações sobre essas metodologias, suas aplicações ao ensino de PLE e outros aspectos teóricos adotados por nós em nossa prática e neste projeto. Em Diesel e Carvalho (2019), as autoras relatam e analisam suas experiências do emprego de metodologias ativas no ensino de PLE em Macau; e em Fernandes e Silva (2019), as autoras apontam as vantagens da abordagem eclética para o ensino de português como língua de herança.
} 
A seguir, apresentaremos o que entendemos sobre abordagem, métodos e técnicas de ensino, o papel da variação e da interação em nossa prática e a importância de se encarar o professor e a prática do ensino de PLE como diplomacia cultural.

A abordagem é definida como uma força ou filosofia que orienta as ações e as decisões do professor, sendo que as principais ações/decisões são: planejamento, produção de materiais, escolha do(s) método(s) e avaliação dos alunos (ALMEIDA FILHO, 1993). Conforme afirmado anteriormente, fazemos uso da abordagem eclética, que possui pontos em comum com o pós-método. A abordagem eclética consiste em uma flexibilidade na qual o professor faz "escolhas metodológicas que sejam mais coerentes e necessárias, tendo em vista o contexto de ensino aprendizagem" (VILLAÇA, 2008, p. 82). Essas escolhas se dão com base na experiência do professor em sala de aula, pois, diante das limitações das abordagens e as críticas que são feitas aos métodos de ensino por serem, em sua maioria, prescritivos ou descontextualizados, ${ }^{9}$ o ecletismo, ou 'ecleticismo inteligente' (LEFFA, 2016), no nosso entender, quando utilizado de maneira equilibrada, sem radicalismos ou excessos, leva às melhores soluções para atender às necessidades do aluno nas situações cotidianas dentro e fora da sala de aula de PLE, já que o professor terá liberdade de escolha e de prática de modo a otimizar seu trabalho e tornar plural o processo de ensino-aprendizagem. ${ }^{10}$

O pós-método (KUMARAVADIVELU, 2001, 2006) possui características em comum com o ecletismo, especialmente seus três elementos principais que, segundo Leffa (2016), são: a busca da autonomia do professor, a aprendizagem baseada em projetos e tarefas e a proposta de uma pedagogia crítica.

A busca da autonomia do professor refere-se a o docente não ficar preso a construtos teóricos, mas exercer sua autonomia por meio de decisões próprias com base em suas ações, práticas e investigações. Já a aprendizagem baseada em projetos e tarefas constitui-se em o professor transformar o aluno em sujeito e protagonista de sua aprendizagem, estimulando-o a perguntar, formular hipóteses e testá-las, coletar dados etc., apenas com a sugestão, a orientação e o direcionamento do professor. ${ }^{11}$ Vale lembrar que a pedagogia crítica consiste no fato de o aluno formar um conhecimento que possa ser usado para as mudanças sociais e não apenas um conhecimento puramente teórico e enciclopédico.

O método é um conjunto de regras, com base na abordagem e nas experiências que o professor possui sobre os alunos, a sala de aula e a língua-alvo (ALMEIDA FILHO, 1993). Desta maneira, a escolha do método pelo professor é influenciada por vários fatores, mas são dominantes sua formação e sua abordagem. Partindo de nossa abordagem eclética e do pós-método, adotamos principalmente os métodos comunicativos - que não se tratam de apenas um único, conforme Almeida Filho (1993) informa, "mas sim a adoção de princípios mais amplos como o foco no processo, nas maneiras específicas de como se aprende e de como se ensinam línguas" (FRANCO; ALMEIDA FILHO, 2009, p. 18) -, buscando adquirir a língua-alvo para que o aluno possa construir um discurso e realizar ações sociais e culturais conscientes e adequadas. ${ }^{12}$ Os métodos comunicativos também não deixam de lado o ensino de gramática (ALMEIDA FILHO, 1993), mas o fazem objetivando a significação e a relevância das mensagens, em situações reais de uso da língua; assim, reduz o emprego de nomenclatura gramatical, apresenta tolerância quando o aluno utiliza sua L1 e procura interpretar os desvios e não os encarar como erros.

\footnotetext{
9 Para uma sistematização dessas críticas, ver Brown (2001) e Larsen-Freeman (2003).

10 Apesar de considerar o ecletismo como uma escolha válida para a sala de aula, por parte do professor, Leffa (2016) chama a atenção para o fato de alguns autores, como Barasch e James (1994), consideram a conciliação de ideias opostas como uma 'obscenidade intelectual'. Já Almeida Filho (1993) afirma que as ações conflitivas da abordagem eclética podem ser resolvidas na prática docente, pois reflexões e rupturas podem ter efeitos retroativos ou proativos nas ideias e práticas do professor. Compartilhamos deste posicionamento, pois encaramos que não se trata de um posicionamento contraditório, mas de estar aberto para pensar em diferentes estratégias e soluções para as situações de sala de aula, visando sempre o melhor para o aprendizado do aluno.

${ }^{11}$ Esta característica do pós-método está em concordância com as metodologias ativas de ensino.

${ }^{12}$ Em Almeida Filho (2005), há uma proposta de ensino de L2/LE toda voltada para a comunicação. Por isso utilizamos os pressupostos teóricos deste autor, pois ele se preocupa com o ensino de LE em geral, de PLE e dos métodos comunicativos.
} 
Consideramos que os métodos comunicativos, além de estarem em conformidade com nossa abordagem eclética e do pós-método, dá espaço para o aluno aprender a língua de maneira mais livre e consciente, inserida em seu uso real, social e cultural, o que torna o aprendizado mais fácil e estimulante. Ademais, os métodos comunicativos são os que mais levam em consideração os aspectos variacionistas, funcionais, interacionais e culturais da língua.

Conforme explicaremos melhor na próxima seção, nossos planejamentos são baseados em tarefas e em conteúdos, tendo como objetivo principal ensinar o público-alvo a interagir em língua portuguesa nas mais diferentes situações do dia a dia (desde as mais informais até as formais), nas modalidades oral e escrita, por meio dos gêneros textuais mais empregados e reconhecendo a ampla variação que o português sofre, tanto no Brasil quanto nos demais países em que é falado. Por isso, nossos cursos e atividades são voltados para a interação, porém sem deixar de também considerar aspectos estruturais, mas que são ensinados dentro de situações de interação e contextualizados.

Finalmente, a técnica é caracterizada como todo tipo de recursos, práticas e/ou atividades que o professor utiliza em sala para atingir os objetivos de suas aulas e do planejamento. Vale dizer que a maioria das técnicas utilizadas em nossa sala de PLE é guiada pela abordagem comunicativa e pela nossa formação docente (professor-pesquisador, pesquisa-ação e metodologias ativas), conciliando, assim, em nossa prática, essas teorias, que estão, a nosso ver, em conformidade umas com as outras, pensando tanto na formação, na atualização e no pensamento crítico do professor e dos alunos, como oferecendo autonomia ao aluno para se desenvolver a seu modo, no seu ritmo e de acordo com seus objetivos.

Desta maneira, enfatizamos que encaramos a língua como interação, e por isso adotamos em nossa prática a abordagem e os métodos comunicativos, pois visamos desenvolver em nossos alunos as competências gramatical, sociolinguística, discursiva e estratégica (CELCE-MURCIA, 2007). Ademais, consideramos que as práticas de professor-pesquisador, da pesquisa-ação e as metodologias ativas estão em conformidade com as práticas de sala de aula, principalmente as atividades e tarefas desenvolvidas pelo professor de PLE, fazendo uso das atividades comunicativas (ALMEIDA FILHO; BARBIRATO, 2000), que são práticas em sala de aula com dados reais de comunicação e que têm um foco na interação. ${ }^{13}$

Para ilustrar como ocorre toda essa conciliação de teorias em nossa prática docente, faremos uma exposição de uma técnica empregada por nós no ensino de PLE, que é a atividade denominada 'temas brasileiros', bem como trazemos também algumas sugestões para desenvolver e adaptar tal tarefa, caso seja necessário.

\section{Cultura Brasileira em Prática: debate, pesquisa, jornalismo e correção}

Guiamos nossas técnicas, nas quais as atividades se encontram inseridas, principalmente nos exemplos positivos da pesquisa-ação, das metodologias ativas, da Linguística Aplica e do ensino de línguas estrangeiras. Ressaltamos que, apesar de seguirmos tais exemplos de técnicas, não simplesmente as copiamos, mas adaptamos de acordo com a comunidade, o público-alvo e seus objetivos ao decidir aprender a língua portuguesa.

A atividade que será descrita aqui, intitulada 'temas brasileiros', tem uma influência de atividades/ projetos de portfólios culturais, que consistem em uma técnica voltada tanto para o ensino de língua e cultura como para avaliar o quanto os alunos estão aprendendo sobre ambos os tópicos (LEE, 1997; BYON, 2007; SCHULTZ, 2007; SU, 2011; MOUTINHO; ALMEIDA FILHO, 2015). Digno de nota é que o portfólio cultural leva em consideração os objetivos do aluno ao aprender a língua-alvo (SCHULTZ, 2007), instiga os

\footnotetext{
${ }^{13}$ Segundo Almeida Filho e Barbirato (2000), que fazem uma revisão dos conceitos de 'tarefa', há uma diferença entre ambos, sendo que 'atividade' possui um significado mais amplo, pois se trata de um "termo genérico para ações realizadas na sala que são reconhecidas como orgânicas e encontráveis na vida fora da sala de aula” (p. 29), enquanto 'tarefa' é um conceito mais específico, consistindo em ações orientadas pelo professor para que o emprego da língua-alvo em sala de aula seja mais próximo da realidade.
} 
processos de reflexão e autoavaliação (LEE, 1997; SCHULTZ, 2007) e apresenta atividades de ensino voltadas para a língua e a cultura em uso (LEE, 1997; BYON, 2007).

Assim, apesar de não conduzirmos a elaboração de um portfólio cultural em nossos cursos, pois não estava entre os objetivos que esperávamos alcançar, nossas atividades apresentam algo dessa técnica, pelo fato de estar em concordância com a diplomacia cultural e a abordagem comunicativa, que já expusemos anteriormente, visto que Moutinho e Almeida Filho (2015), ao relacionarem a diplomacia cultural e o ensino de PLE, mencionam alguns exemplos e atividades de portfólio cultural, especialmente a de Su (2011).

Tendo isso em mente, a atividade 'temas brasileiros' enfoca o debate, a pesquisa, a interculturalidade, a autoavaliação, o trabalho em grupo, o pensamento crítico, a produção de diferentes gêneros textuais (diálogo, reportagem, relatório etc.) e situações, reais ou simuladas, do uso da língua portuguesa, como detalharemos posteriormente. Antes de descrevermos nossa atividade, faremos algumas considerações sobre nosso planejamento.

O planejamento de nossos cursos é feito baseado em tarefas e em conteúdos. ${ }^{14} \mathrm{O}$ público-alvo com o qual nos deparamos localiza-se nas duas extremidades de proficiência, ou seja, básico ou avançado. ${ }^{15}$ Como nos foi exigido pensarmos antecipadamente os objetivos, as habilidades, as competências e os conteúdos, nós os elaboramos de maneira relativamente flexível, com um certo espaço para serem adaptados especificamente para cada turma e modificados de acordo com suas demandas. Isso se mostrou vantajoso em nossa prática, pois, caso seja necessário fazer um planejamento para um curso intermediário (nível B no QECR), cursos de português para fins específicos, entre outros, nós já temos modelos prévios para a instituição em que atuamos, que foram testados com sucesso em cursos anteriores e que servem como base para a elaboração de planejamentos futuros.

Optamos pelo planejamento baseado em tarefas pelo fato de este focar na comunicação ${ }^{16}$ (BEGLAR; HUNT, 2002), dando oportunidade aos alunos de aprenderem a usar a língua em situações comunicativas reais, por meio de tarefas que procuram simular tais usos. Em alguns momentos, empregamos também, em nosso planejamento, a orientação voltada para conteúdos, já que neste tipo de planejamento, de acordo com Byrnes (2005), relaciona-se o ensino de língua e cultura de uma maneira comunicativa, ponto principal de nossa abordagem. ${ }^{17}$

Não discorremos aqui a respeito das relações entre língua e cultura, tampouco das questões interculturais no ensino de língua estrangeira; para isso remetemos o leitor à obra de Kramsch (1993), que consideramos uma referência substancial no assunto, e a uma breve reflexão, porém esclarecedora, que Ferreira (1998) e Almeida Filho (2002) fazem sobre esse tema. ${ }^{18}$

\footnotetext{
${ }^{14}$ Sobre planejamento de cursos de línguas, além das referências que serão citadas posteriormente, ver as ideias de Viana (1997) e de Almeida Filho (2007, 2017), e os trabalhos de Barbirato e Silva (2016) e Macedo (2016), os quais se dedicaram somente a esse assunto.

${ }^{15}$ Não utilizamos a classificação ou os termos do Quadro Europeu Comum de Referência para Línguas (QECR) pelo fato de não considerarmos necessário, pois não era utilizado nos locais em que lecionamos. Apenas para esclarecer o leitor, nosso planejamento é pensado para os falantes básicos, que são A1-A2, enquanto os avançados, são C1-C2. As adaptações ocorreriam para cursos intermediários, falantes independentes, em nível B.

${ }^{16}$ Sobre o ensino comunicativo, ver Almeida Filho (1993) e Franco e Almeida Filho (2009) e os já mencionados no decorrer deste texto.

17 Apesar de empregarmos a abordagem comunicativa e as teorias relacionadas a ela, conforme expomos neste trabalho, enfatizamos também que, caso haja uma necessidade da instituição e/ou dos alunos de cursos específicos de PLE que exijam outra abordagem, como na modalidade de português para fins específicos - podendo ser português instrumental, cursos preparatórios para algum exame (como Celpe-Bras ou pós-graduação), cursos de produção textual etc. -, isso não nos impede de revermos nossa abordagem, colocando em prática o pós-método e diferentes técnicas que estamos acostumados a empregar, visando ensinar melhor e alcançar os objetivos desejados pelos alunos. Os exemplos que mencionamos exigiriam uma abordagem que contemplasse aspectos mais gramaticais e formais do português.

${ }^{18}$ Nas últimas décadas, a bibliografia sobre cultura e ensino de língua é vasta, abarcando a Linguística Aplicada, a Pedagogia, os estudos interculturais e até a Antropologia. Em relação ao ensino de PLE, a lista também é grande e continua a crescer, com estudos de caso, relatos de experiências, análise de materiais didáticos etc. Assim, debater sobre esse assunto e realizar uma pesquisa bibliográfica a respeito foge do escopo do presente texto.
} 
Os cursos em que lecionamos tinham uma média de 20 alunos, organizados pelo nível de conhecimento, sendo que nossas turmas eram, em sua maioria, de nível avançado.

Organizamos os conteúdos de nossos cursos em unidades temáticas que refletem situações reais do uso da língua, como o falante em casa, na rua, fazendo compras, pedindo informações, interagindo com a família, alimentando-se, cuidando de sua saúde etc. Assim, as atividades são todas voltadas para a comunicação na situação específica da unidade; da mesma maneira, o vocabulário ensinado pertence ao campo semântico em questão (casa, família, alimentos, saúde).

A carga horária varia entre 60 e 80 horas/aula semestrais, a depender da instituição. Em média, cada etapa das atividades, que descreveremos a seguir, corresponde a 4 horas/aula semanais, sendo divididas em dois dias (duas horas/aula em cada).

O objetivo principal da atividade é desenvolver as habilidades de produção oral e escrita, enfatizando um mesmo tema de cultura brasileira para todas elas; assim, o aluno será orientado em temas voltados para pesquisa bibliográfica, metodologia científica, diferentes gêneros textuais e domínios discursivos distintos. ${ }^{19}$ Entre os objetivos secundários estão: diferenciar gêneros formais e informais, bem como gêneros acadêmicos de gêneros jornalísticos; conhecer algumas etapas e rudimentos da pesquisa científica; identificar e refletir sobre aspectos culturais brasileiros e interculturalidade. Desta maneira, cada etapa da atividade tentará contemplar os assuntos envolvidos na atividade e/ou fazer uma relação entre eles.

O trabalho com os gêneros textuais na aula de PLE vem se mostrando eficaz e está em concordância com o desenvolvimento da competência comunicativa. Apenas um dentre tantos exemplos dessa relação é estudado por Trouche (2007), que relaciona os gêneros textuais, a polifonia e a competência comunicativa no ensino de PLE. Assim, partindo da definição de Marcuschi (2009), que enfatiza os aspectos sócio-históricos dos gêneros textuais, a prática do ensino comunicativo em PLE por meio dos gêneros textuais é importante, pois aborda situações reais de comunicação, traços da cultura brasileira e elementos multimodais, entre outros.

Após as considerações anteriores terem sido feitas, passamos a descrever nossa atividade, a qual foi retirada de um de nossos planejamentos. Organizaremos, primeiramente, uma breve listagem em tópicos das principais etapas, no intuito de tornar mais sistematizado e objetivo para o leitor, para, em seguida, detalhar cada um dos tópicos apresentados.

Digno de nota é que nos referimos a essa atividade com o nome de 'temas brasileiros'. Estamos a par de que tal título não contempla todas as suas etapas; contudo, não quisemos modificá-lo para esta exposição, para mantermo-nos fiéis à nossa prática.

\section{$1^{a}$ etapa (2 horas/aula)}

- Inicialmente, o professor começa realizando um debate a respeito de quais temas sobre o Brasil, ou da cultura brasileira, os alunos já conhecem e quais têm interesse em saber mais;

- Após essa atividade de conversação e de posse das respostas dos alunos, o professor escolhe um dos temas (pode ser o mais votado, o mais atual, o mais interessante, com maior material disponível etc.);

- O professor passa uma atividade de pesquisa e produção textual para casa, orientando as fontes (referências bibliográficas, sites e jornais);

- A produção textual solicitada aos alunos deve ser de acordo com a proficiência da turma (resumo, resenha, fichamento, relato, relatório), explicando sobre o que cada um entendeu a respeito do aspecto pesquisado da cultura brasileira. ${ }^{20}$

\footnotetext{
${ }^{19}$ Vale lembrar que, nessas orientações, o professor oferecerá apenas tópicos básicos sobre esses assuntos, pois não é o objetivo do curso, tampouco da atividade, aprofundar-se nisso.

${ }^{20}$ Deixamos esta $1^{\mathrm{a}}$ etapa somente para as orientações iniciais e esclarecimentos, o que pode parecer pouco, mas preferimos deixar a aula em aberto com o intuito de esclarecer todas as dúvidas que possam surgir dos alunos. Caso a atividade seja compreendida e não haja perguntas, sugerimos que os alunos comecem a fazer em aula mesmo.
} 
$2^{a}$ etapa (2 horas/aula)

- Cada aluno fará uma seleção de trechos de sua produção textual para a leitura em sala de aula;

- Em seguida, cada aluno explicará como fez sua pesquisa e o que aprendeu com ela.

$3^{a}$ etapa (2 horas/aula)

- O professor instigará um novo debate; desta vez, procurando mencionar as informações trazidas nas pesquisas dos alunos e estimulando-os a refletirem sobre questões de mitos, estereótipos e preconceitos;

- Será conduzida também uma autoavaliação para verificar se os alunos modificaram seus/suas pensamentos/opiniões, se realmente aprenderam mais a respeito do tema que selecionaram e quais foram as dificuldades/ inseguranças em utilizar a língua-alvo nas produções oral e escrita.

$4^{a}$ etapa (2 a 4 horas/aula)

- O professor fará diferentes momentos de correção: correção por pares, correção coletiva e correção do próprio professor;

- O produto final é a tarefa da reescrita, que levará em conta os diferentes tipos de correções, bem como ocorrerá em diferentes momentos, contendo tanto a reescrita individual quanto a colaborativa.

$5^{a}$ etapa (opcional/ sugestão) ${ }^{21}$

- O professor pode pensar em realizar um evento na Instituição de Ensino Estrangeira sobre o Brasil, consultando e procurando o apoio de autoridades governamentais brasileiras (consulado ou embaixada) e locais, da direção/coordenação do departamento, do corpo docente e do corpo discente;

- Esse evento poderia contar com apresentações de brasileiros e de estrangeiros, especialmente estimulando os alunos a desenvolverem seus trabalhos elaborados em sala de aula. ${ }^{22}$

Portanto, a primeira etapa da atividade consiste em o professor instigar um debate a respeito de quais temas sobre o Brasil ou sobre a cultura brasileira os alunos já conhecem e quais despertam interesse em conhecer mais. Nesse debate, o professor, como mediador, lançará também certas questões para os alunos refletirem e discutirem em sala, observando aspectos de mitos, estereótipos e preconceitos existentes em relação ao Brasil e à cultura brasileira. ${ }^{23}$ Ressalte-se que essa temática será abordada somente na $3^{a}$ etapa; porém segue aqui um direcionamento para que o professor, em sua fala durante a $1^{\text {a }}$ etapa, já possa adiantar algumas questões para os alunos refletirem.

No segundo momento dessa primeira etapa, o professor, juntamente com os alunos, selecionará/ negociará uma maneira específica para escolher um tema a ser trabalhado por eles nas próximas aulas. Aqui

\footnotetext{
21 Apesar de prevermos esta possibilidade, sabemos da dificuldade que é organizar um evento dessa magnitude, por isso colocamos somente como uma sugestão em nosso planejamento e para a atividade, não contando como hora/aula. Afirmamos isso, pois nós mesmos, apesar de nossos esforços, sofremos, em nossas tentativas, bastantes limitações, tanto em relação ao apoio e/ou autorizações quanto ao corpo discente, o que até hoje nos impossibilitou de realizar algum evento desse tipo, que poderia marcar o final do semestre ou do ano letivo positivamente.

22 Deixamos esta etapa em aberto pelo fato de que temos conhecimento do quanto é complexo a organização de um evento de nível acadêmico/cultural. Por isso, apontamos apenas algumas características que o evento poderia ter, já que os detalhes serão delimitados por organizadores, órgãos financiadores, instituição, local etc.

23 Apenas para citar os mitos, estereótipos e preconceitos recorrentes em nossos alunos, que após uma breve pesquisa pela internet se revelou comum a cidadãos de vários países: todos os brasileiros gostam e jogam futebol, e também conhecem ou são fãs de jogadores como Ronaldinho Gaúcho, Kaká e Neymar; a população inteira brasileira é homogênea, sendo formada por negros, mulatos e índios; o Brasil possui festas em grande parte do ano, sendo todas elas com samba e seguindo os moldes do carnaval carioca; o país é extremamente violento, ocorrendo roubos e conflitos armados constantemente em todas as cidades.
} 
destaca-se a questão da negociação entre os pares e entre professor-aluno. Ademais, o professor pode propor os métodos de escolha aos alunos, como votação, a atualidade do tema, a facilidade para a pesquisa, entre outros, ou perguntar-lhes se eles têm algo em mente para compartilhar com a turma. Vale lembrar que, antes de iniciar esse processo de negociação, o professor deve instruir os alunos, de maneira resumida, sobre como serão as próximas etapas da atividade.

Observamos que, somente nessas duas etapas iniciais, o professor de PLE já trabalhou a atividade de conversação e diferentes gêneros textuais orais, ${ }^{24}$ destacando-se o diálogo, a discussão, o debate e a exposição oral (tanto o professor - explicações, conversas - quanto os alunos - a leitura da produção textual e a explicação de como fez a pesquisa). Assim, se considerar necessário, o professor pode fazer uma breve intervenção/ observação apenas para comentar isso com os alunos..$^{25}$

Ainda na primeira etapa da atividade com o tema selecionado, o professor deve instruir detalhadamente qual serão os exercícios cobrados para as próximas aulas e quais os objetivos que se pretende alcançar. Pedirá uma produção textual escrita a respeito do tema brasileiro escolhido, com base numa pesquisa, sendo que ambas (a pesquisa e a produção textual) serão feitas fora de sala de aula. Enfatizamos que o gênero escolhido da produção textual deve estar de acordo com a proficiência da turma. Geralmente selecionamos um relato de experiência ou um relatório, quando os alunos se sentem mais seguros na produção na língua-alvo, ou apenas um resumo, quando ainda existem certas dificuldades e/ou inseguranças.

Em nossa turma de nível avançado, a produção escrita foi solicitada em formato de um artigo, já pensando em adaptar para o formato de comunicação oral a ser apresentada no evento que planejamos na $5^{a}$ etapa (infelizmente, não conseguimos organizar tal evento em nossa prática docente). Esse artigo também é um documento de avaliação para o aluno; será lido e corrigido pelo professor, que lhe atribuirá uma nota.

Em relação à pesquisa, temos o costume de orientar os alunos a procurarem inicialmente o tema pela internet e a darem maior atenção a sites de notícias e jornais. Caso os alunos sintam-se seguros na leitura, aconselhamos também uma busca em banco de dados acadêmicos, com o intuito de verificar se há artigos científicos sobre o tema brasileiro selecionado. Vale lembrar que, tanto o tema selecionado quanto as atividades organizadas pelo professor, além da proficiência dos alunos, devem ter em mente também os objetivos que eles almejam ao aprender a língua portuguesa.

Ao finalizar essa primeira etapa, o professor pode, novamente, inserir alguns aspectos teóricos, caso não tenham sido trabalhados anteriormente, sobre: gêneros e suporte textuais, ao falar de sites e jornais; domínios discursivos, com o destaque do jornalismo e os vários gêneros relacionados a esse domínio, como editorial, reportagem, artigo de opinião, crônica; gêneros textuais acadêmicos, como resumo, relatório, relato de experiência, artigo científico, entre outros. ${ }^{26}$

$\mathrm{Na}$ segunda etapa, o professor pede que cada aluno leia para a turma sua produção escrita, ou selecione algum trecho (a depender do tamanho), bem como solicita que explique como fez sua pesquisa e o que aprendeu com ela. Destacamos aqui que essa etapa pode ser feita num formato de roda de conversa, modificando o ambiente da sala de aula, ou até mesmo ocorrendo essa aula em um outro ambiente da instituição, para que os alunos possam se sentir mais livres e interagir melhor. Ademais, os aspectos teóricos que o professor pode destacar aos alunos é o da leitura em voz alta de um gênero escrito, que se diferencia do gênero oral; a

\footnotetext{
${ }^{24}$ Empregamos a diferença entre atividade e gênero de Fairclough (2003) e retomada em Travaglia et al. (2013).

${ }^{25}$ Seguindo os pressupostos da abordagem comunicativa, bem como de acordo com o perfil da turma, as considerações teóricas no decorrer das aulas dessa atividade são reduzidas, apenas teorizando e chamando a atenção ao que o aluno já conhece e colocou em prática. Não dedicamos muitas aulas a conteúdos gramaticais e/ou teóricos, tampouco utilizamo-nos de longas explicações e de terminologia científica quando estas não se adequam ao público-alvo da turma de PLE, por exemplo: falantes jovens ou de baixa escolaridade.

${ }^{26}$ Sobre a terminologia de Linguística Textual e áreas afins aqui empregada, ver Marcuschi (2009).
} 
retomada dos gêneros orais e as estratégias de retextualização (MARCUSCHI, 2000), ao se transformar um gênero textual escrito (a pesquisa do aluno) para a oralidade (a apresentação).

$\mathrm{Na}$ etapa anterior, bem como nas terceiras e quarta etapas, damos espaço para os alunos interagirem, fazerem uma autoavaliação, avaliação da produção dos colegas e explicar como foi feita sua pesquisa/produção. Destacamos essas tarefas pelo fato de serem tarefas comunicativas e estarem relacionadas com estratégias de aprendizagem específicas e com a autorregulação de aprendizagem. Segundo Silva, Simão e Sá (2004), a autorregulação da aprendizagem consiste nas atitudes e nas motivações do aprendiz em seu próprio processo de aprendizagem. Assim, empregamos sempre, em nossos cursos de PLE, algumas atividades desse tipo, para verificar principalmente como está o grau de motivação de nossos alunos em relação a nós, ao curso e à aprendizagem da língua portuguesa.

Na terceira etapa, ocorrerá um novo debate; porém a ênfase será dada em mitos, estereótipos e preconceitos que os estudantes poderiam ter a respeito do Brasil (dos brasileiros e/ou da cultura brasileira) e se a atividade 'temas brasileiros' conseguiu modificar positivamente os alunos. É possível aqui, a depender das respostas e da turma, realizar uma dinâmica estilo 'antes e depois' (podendo ser feita no quadro, em cartazes, post-it ou roda de conversa), na qual cada aluno apontaria seu pensamento a respeito do tema pesquisado da cultura brasileira antes da atividade e o que ele aprendeu ou mudou depois dela. O professor deve desfazer os mitos - por exemplo, os relacionados ao futebol, ao samba e à violência, entre outros -, enfatizando a importância de que o Brasil, por sua miscigenação e suas dimensões continentais, não pode ser pensado como um bloco homogêneo, pois é um país multicultural, com suas cidades, estados e regiões apresentando diferentes traços culturais. Nessa etapa, ainda, o professor aproveitará o clima de conversa e a descontração da dinâmica para solicitar aos alunos que se autoavaliem em relação às dificuldades ou inseguranças encontradas nas etapas da pesquisa, da leitura e das produções textuais.

$\mathrm{Na}$ posse da autoavaliação dos alunos, que é feita oralmente - mas, recomenda-se que o professor tome notas das observações individuais -, a quarta etapa é dedicada à revisão/correção da produção textual. Seguindo o pressuposto de diferentes tipos de revisão (MIRANDA; FERRAZ, 2014; MAFRA; BARROS, 2017), optamos por realizar o primeiro momento dessa etapa com a correção por pares, na qual um membro da dupla lerá e fará sugestões/alterações no texto do outro em sala de aula, sendo que todas as duplas serão supervisionadas pelo professor que, no decorrer da aula, ficará consultando cada uma delas para verificar o andamento desse exercício. ${ }^{27}$ Prevemos a correção coletiva, bem como a reescrita colaborativa, mas não a consideramos como um momento obrigatório dos 'temas brasileiros', pois o professor terá que, de acordo com sua experiência e conhecimento da turma, levar em consideração o fato de que a correção coletiva poderá causar desconforto, constrangimento, aumentar a insegurança linguística, ou seja, deverá avaliar se a turma está preparada ou não para esse momento. Caso não esteja, haverá, em seguida, a correção do professor.

Em nossa correção, utilizamos um método que consideramos ajudar na reescrita, consistindo em sublinharmos de uma cor o que chamamos apenas de 'inconsistências' - que são, na verdade, os desvios da norma-padrão -, e marcamos com uma cor distinta (geralmente vermelho) e com um destaque maior (circulando) um erro à estrutura da língua portuguesa, com algum elemento inexistente. Não colocamos a forma correta, apenas expomos aos alunos esse sistema de marcação e de cor, sendo que, na reescrita, o aluno deverá repensar

\footnotetext{
${ }^{27}$ Para a correção/revisão há duas opções: deixarmos os alunos livres ou elaborar, para entregar a eles, uma ficha de revisão, também chamada de 'grade de controle' (MAFRA; BARROS, 2017). Verificamos, a partir de nossa experiência, que deixar os alunos livres para efetuar as correções, sem algum tipo de guia ou orientação, funciona somente em/com turmas/alunos específicos, que já são proficientes, seguros, apresentam alta escolaridade e/ou já conhecem algum tipo de método de correção, geralmente de cursos anteriores de PLE ou de outra língua estrangeira. Caso não, o aluno pode ficar perdido e não saber o que fazer, tampouco o que fazer ou por onde começar. Em nossa ficha de revisão colocamos respostas objetivas ('sim' ou 'não'), espaço para comentários e as avaliações geralmente versam sobre os seguintes elementos: o título, o tema, a linguagem utilizada, a estrutura do gênero, a compreensão e os aspectos gramaticais.
} 
e tentar reconhecer o porquê de sua construção ter sido marcada. Apenas como exemplo, separamos duas construções que marcamos e devolvemos aos alunos; desvios e erros que analisamos como graves:

1. Os brasileiros gosta muito de braçar, mas tem gente que não gosta.

2. A pesquisa mostrou muitas informações e notícias sobre o Brasil esse.

Em (1), o sublinhado do exemplo corresponde ao sublinhado que fazemos, pois trata-se de um desvio na concordância, muito comum em diferentes variedades e empregado até mesmo por falantes nativos do português, enquanto braçar, que destacamos aqui em itálico, marcamos em vermelho para o aluno, sendo que o mesmo ocorreu em (2) para Brasil esse. Chegamos a nos preocupar com este último e consultamos o aluno, pois é uma construção pouco vista, mesmo na produção textual de aprendizes de PLE, e também pelo fato de o aluno já ser avançado em português. A explicação do aluno foi pertinente, pois ele afirmou ter ouvido em vídeos de humor on-line de brasileiros, expressões como ‘ai, brasilzão, esse daí!' ou 'ô Brasil, esse véio de guerra!' e interpretou algo como a existência de um composto 'Brasil esse' que fosse empregado com efeito de humor pelos brasileiros.

Ao receber os textos de volta, o professor pode realizar diferentes momentos de reescrita na sala: reutilizar os mesmos pares para que ocorra uma ajuda mútua; selecionar trechos para projetar (sem identificar o aluno) tanto de exemplos de bons textos (para dar um feedback positivo e recompensar coisas boas), quanto de problemas graves ou recorrentes em vários textos; caso seja possível, realizar a escrita colaborativa presencial, que pode ocorrer das interações entre todos os colegas em sala, ou virtual, por meio de fóruns, sala de batepapo ou plataformas específicas para isso. Após todos esses momentos terem ocorrido, é necessário também o aluno ter o momento para si, efetuando a reescrita individual como produto final de sua produção textual.

Digno de nota é que alguns aspectos teóricos previstos ou mais detalhados da atividade 'temas brasileiros' preveem um público-alvo adulto e de alta escolaridade. No nosso caso, aplicamos em turmas de graduandos e graduados. Caso o público-alvo seja distinto, essa atividade pode ser adaptada de várias formas, reduzindo ou cortando alguns momentos ou algumas etapas. Ademais, outra adaptação que ela pode sofrer é o enfoque dado para alguns dos elementos, a saber, os gêneros textuais e os temas trabalhados.

$\mathrm{Na}$ sequência, falaremos brevemente de duas adaptações que já realizamos dessa atividade. A primeira intitulamos 'O Brasil na mídia' e a segunda, 'Brasil e os brasileiros'. Em ‘O Brasil na mídia', fizemos as etapas muito semelhantes, porém focamos nas atividades do jornal como suporte, explicamos algumas coisas de hipertexto e dos gêneros textuais do jornalismo, e demos atenção ao tema de como o Brasil é representado na mídia do país de cada aluno. ${ }^{28}$

A segunda atividade que desenvolvemos é chamada 'Brasil e os brasileiros'. Esta atividade é similar, porém o debate pode ter um tom mais sério, apontando certas peculiaridades sociais, políticas, históricas, antropológicas, entre outras, do Brasil, ou um tom mais informal, com os alunos falando sobre o que mais gostam do Brasil, da cultura brasileira ou nos cidadãos brasileiros. O destaque aqui será feito aos gêneros textuais acadêmicos, exigindo maior proficiência e alta escolaridade, tendo ligação também com a etapa opcional de apresentação dos trabalhos, apresentada logo mais. Haverá, aqui, a etapa de pesquisa e de produção textual, porém o professor deverá retomar/orientar sobre a metodologia da pesquisa científica, bem como explicar a

\footnotetext{
${ }^{28}$ Isso pressupondo que o público-alvo sejam alunos de diferentes nacionalidades. Há também o exemplo contrário, no qual o professor de PLE é que ensina no país e na instituição estrangeiros; assim, caberia somente uma adaptação de como o Brasil é retratado na mídia local. Caso não haja notícias sobre o Brasil, recomendamos que se faça uma pesquisa na mídia internacional (em outras línguas, caso seja possível, de acordo com o perfil dos alunos) ou que se faça uma discussão e interpretação dos motivos de o Brasil não aparecer no jornalismo específico do país do aluno.
} 
estrutura do gênero acadêmico que deseja. Já o processo de correção será próximo a uma orientação, pois o professor solicitará, com seu auxílio, que os alunos reescrevam seus textos de maneira mais formal, para desenvolver uma hipótese de pesquisa que deverá ser verificada também com a ajuda do professor. O professor, com as hipóteses em mãos, auxiliará a pesquisa dos alunos por meio de entrevistas com os corpos docente e discente da universidade, com brasileiros residentes no país (caso isso se aplique), em manifestações artísticas brasileiras ou bibliografia de pesquisas sobre o Brasil, dependendo de quais hipóteses foram formuladas pelos alunos.

É a partir do produto final da atividade 'temas brasileiros', ou de suas adaptações, conforme as duas ideias anteriores, que pensamos na organização de uma 'Semana do Brasil' ou 'Semana do Brasil em (...)', cujo nome da instituição/curso ou cidade/país poderia ser colocado no título do evento. Essa 'Semana do Brasil' contaria com a apresentação de alguns trabalhos dos alunos de PLE, a presença do embaixador ou cônsul do Brasil, funcionários da embaixada/consulado e cidadãos brasileiros residentes no país, que tivessem vontade de conversar com os estudantes ou palestrar algo sobre si ou sobre o Brasil, sem contar que as autoridades do locais e os demais membros do corpo docente seriam, também, convidados e instigados a participar e contribuir com o evento, com o intuito de estreitar os laços entre as duas nações e as culturas lusófonas e local.

Finalmente, após a exposição de nossas atividades, esperamos ter deixado clara a função do professor de PLE como um diplomata cultural, pois, durante o curso de PLE e as atividades em sala e fora dela, o professor se preocupa em ensinar a língua portuguesa e a cultura brasileira de uma maneira positiva e participativa, ouvindo os alunos e instigando-os a se interessar e a gostar ainda mais do Brasil, não esquecendo de apresentar aspectos benéficos de se estudar o português e a cultura dos demais países lusófonos. Com debates e interações em sala, o professor também demonstra interesse nas opiniões dos alunos e suas respectivas ideias e traços culturais. Ademais, por meio da divulgação dos trabalhos dos alunos e a possibilidade da organização de um evento, o professor de PLE acaba por fortalecer as relações diplomáticas e culturais entre os governos e os indivíduos, chamando a atenção sempre para o português e a cultura brasileira por meio de seu trabalho.

\section{Considerações Finais}

A língua portuguesa vem ganhando espaço no mundo e seu ensino, nas diferentes modalidades (segunda língua, língua estrangeira, língua de herança), vem crescendo significativamente nas últimas décadas. Por isso, merecem destaque tanto a formação do professor de PLE, bem como seu papel nesse processo.

Este estudo é fruto de nossas pesquisas e práticas, e com ele objetivamos expandir e contribuir para a prática do professor de PLE. Assim, argumentamos que o professor de PLE tem uma função notória, que é a de um diplomata cultural, no cenário internacional atual em que a diplomacia pública e o poder suave possuem muito mais espaço do que imposições e conflitos bélicos, sendo muito mais saudáveis e benéficos. Desta maneira, consideramos que as teorias do professor-pesquisador, da pesquisa-ação e das metodologias ativas, juntamente com a delimitação correta de abordagens, métodos e técnicas de ensino de língua estrangeira, são também fundamentais para o professor de PLE.

Ademais, na tentativa de expandirmos nossa contribuição, trouxemos uma atividade que entrelaça nossas concepções teóricas com o ensino de PLE e a cultura brasileira, levando em consideração o diálogo, o debate, o ato de ouvir o Outro (no caso, as opiniões e traços culturais dos alunos) e desfazer mitos, estereótipos e preconceitos em relação ao Brasil. Além disso, fornecemos opções de desenvolvimento e adaptações de nossa atividade a diferentes perfis de alunos e turma.

Finalmente, temos consciência que, mesmo com nossos esforços, em conjunto com os esforços dos demais professores, pesquisadores e interessados no assunto, o caminho para a expansão da língua portuguesa 
no mundo e da atuação do professor de PLE ainda é longo, necessitando de uma política linguística clara e atuante por parte do governo brasileiro, em níveis nacional e internacional. Também faz-se necessário o suporte de diferentes setores governamentais, além de MEC e MRE, que podem auxiliar o trabalho do professor de PLE e fomentar a pesquisa, a valorização, a formação etc. - principalmente o Ministério da Ciência, Tecnologia e Inovações (MCTI) e o Ministério do Turismo (MTur), juntamente com diversas secretarias e departamentos existentes. A partir do interesse e de investimentos do setor público, isso despertaria o interesse da iniciativa privada, que passaria a também investir na área. Esse é o nosso voto de esperança para o futuro da língua portuguesa.

\section{REFERÊNCIAS}

ALMEIDA FILHO, J. C. P. de. Dimensões comunicativas no ensino de línguas. Campinas: Pontes, 1993.

ALMEIDA FILHO, J. C. P. de. Língua além de cultura ou além da cultura, língua? Aspectos do ensino da interculturalidade. In: CUNHA, M. J. C.; SANTOS, P. (org.). Tópicos em Português Lingua Estrangeira. Brasília: EdUnB, 2002. p. 209-215.

ALMEIDA FILHO, J. C. P. de. Lingüistica Aplicada: ensino de língua e comunicação. Campinas: Pontes, 2005.

ALMEIDA FILHO, J. C. P. de. O planejamento de um curso de língua: a harmonia do material-insumo com os processos de aprender, ensinar e refletir sobre a ação. 2007. Disponível em: https://bit.ly/3lWv5T9. Acesso em: 02 abr. 2020.

ALMEIDA FILHO, J. C. P. de. Fundamentos de abordagem e formação de professores de línguas. Campinas: Pontes, 2011.

ALMEIDA FILHO, J. C. P. de. Ensinar línguas começando pelo plano de curso. Revista de Estudos de Cultura, v. 7, n. 1, p. 71-82, 2017.

ALMEIDA FILHO, J. C. P. de; BARBIRATO, R. C. Ambientes comunicativos para aprender língua estrangeira. Trabalhos de Lingüistica Aplicada, v. 36, p. 23-42, 2000.

ANDRÉ, M. Pesquisa, formação docente e prática docente. In: ANDRÉ, M. (org.). O papel da pesquisa na formação e na prática dos professores. Campinas: Papirus, 2001. p. 55-69.

AUSTIN, J. L. How to do things with words. 2th ed. Oxford: Oxford University Press, 1975.

ANG, M. I.; ISAR, Y. R.; MAR, P. Cultural diplomacy: beyond the national interest? International Journal of Cultural Policy, v. 21, n. 4, p. 365-381, 23 jun. 2015.

ARNDT, R. The first resort of kings. American Cultural Diplomacy in the Twentieth Century. Washington: Potomac Books, 2006.

BARASCH, R. M.; JAMES, C. V. Beyond the monitor model. Comments on the current theory and practice of in SLA. Boston: Heinly and Heinly, 1994. 
BARBIRATO, R. C; SILVA, V. L. Planejamento de cursos de línguas: traçando rotas e explorando caminhos. Campinas: Pontes, 2016.

BEGLAR, D.; HUNT, A. Implementing task-based language teaching. In: RICHARDS, J.; RENANDYA, W. (ed.). Methodology in language teaching: An anthology of current practice. Nova York: Cambridge University Press, 2002. p. 2276-2280.

BORGES, E. G. Política linguística e o ensino do português como língua estrangeira (PLE): uma investigação sob a perspectiva da pragmática. 2015. Dissertação (Mestrado em Estudos Linguísticos) - Universidade Federal de Uberlândia, Uberlândia, 2015.

BROWN, H. D. Teaching by principles: an interactive approach to language pedagogy. São Francisco: Longman, 2001.

BYON, A. S. The use of cultural portfolio project in Korean culture classroom: Evaluating stereotypes and enhancing cross-cultural awareness. Language, Culture, and Curriculum, v. 20, n. 1, p. 1-19, Mar. 2007.

BYRNES, H. Content-based foreign language instruction. In: SANZ, C. (ed.). Mind and context in adult second language acquisition: Methods, theory, and practice. Washington: Georgetown University Press, 2005. p. $282-$ 302.

CARVAlHO, A. M. O ensino de ciência por investigação: condições para implementação em sala de aula. São Paulo: Cengage Learning, 2013.

CARVALHO, A. M.; LUCCHESI, D. Portuguese in contact. In: WETZELS, L.; COSTA, J.; MENUZZI, S. (ed.). The Handbook of Portuguese Linguistics. New Jersey: John Wiley \& Sons, 2016. p. 41-55.

CASTELLAR, M. V. Metodologias ativas. Ensino por investigação. São Paulo: FTD, 2016.

CASTRO NETO, F. História do futuro: diagnóstico e perspectivas de políticas públicas para o ensino/ aprendizagem de PLE-PL2 no Brasil do século XXI. 2013. Dissertação (Mestrado em Linguística Aplicada) - Universidade de Brasília, Brasília, 2013.

CELCE-MURCIA, M. Rethinking the role of communicative competence in language teaching. In: SOLER, E. A.; JORDÀ, M. P. (ed.). Intercultural language use and language learning. Dordrecht: Springer, 2007. p. 41-57.

CHAGAS, L. A. Entre experiências e indícios: o ensino de português para estrangeiros em contexto de imersão linguística. 2016. Dissertação (Mestrado em Linguística) - Universidade Federal de Uberlândia, Uberlândia, 2016.

CULL, N. Public diplomacy: Taxonomies and histories. The Annals of the American Academy of Political and Social Science, v. 616, n. 1, p. 31-54, Mar. 2008.

DIESEL, A.; CARVALHO, S. Ensino do português como língua estrangeira mediado por metodologias ativas de ensino: um relato de experiências realizado em Macau/China. In: OSÓRIO, P.; GONÇALVES, L. (org.). O ensino do português como língua não materna: metodologias, estratégias e abordagens de sucesso. Rio de Janeiro: Dialogarts, 2019. p. 282-309.

EXX AFRICA. Africa Investment Risk Report 2019. 16 jan. 2019. Disponível em: https://bit.ly/3mZ5sT3. Acesso em: 02 abr. 2020. 
FAIRCLOUGH, N. Analysing discourse: textual analysis for social research. Londres; Nova York: Routledge, 2003.

FERNANDES, E.; SILVA, R. A adoção de uma abordagem eclética: da avaliação-diagnóstica à elaboração de um syllabus orgânico em turmas mistas com falantes/aprendizes de português como língua herança. In: OSÓRIO, P.; GONÇALVES, L. (org.). O ensino do português como língua não materna: metodologias, estratégias e abordagens de sucesso. Rio de Janeiro: Dialogarts, 2019. p. 310-338.

FERREIRA, I. A. Perspectivas interculturais na sala de aula de PLE. In: SILVEIRA, R. (org.). Português língua estrangeira: perspectivas. São Paulo: Cortez, 1998.

FRANCO, M. A. S. Pedagogia da pesquisa-ação. Educação e Pesquisa, São Paulo, v. 31, n. 3, p. 483-502, set./ dez. 2005.

FRANCO, M. M.; ALMEIDA FILHO, J. C. P. de. O conceito de competência comunicativa em retrospectiva e perspectiva. Revista Desempenho, v. 10, n. 1, p. 4-22, jun. 2009.

KRAMSCH, C. Context and culture in language teaching. Oxford University Press, 1993.

KUMARAVADIVELU, B. Toward a postmethod pedagogy. TESOL Quartely, v. 35, n. 4, p. 537-560, 2001.

KUMARAVADIVELU, B. Understanding language teaching: from method to postmethod. Londres: Lawrence Erlbaum Associates, 2006.

LARSEN-FREEMAN, D. Techniques and principles in language teaching. Oxford: OUP, 2003.

LEE, L. Using portfolios to develop L2 cultural knowledge and awareness of students in intermediate Spanish. Hispania, v. 80, n. 2, p. 355-367, May 1997.

LEFFA, V. J. Lingua estrangeira. Ensino e aprendizagem. Pelotas: EDUCAT, 2016.

MACEDO, C. (Re)planejamento como política institucional de ensino de línguas. 2016. Dissertação (Mestrado em Linguística Aplicada) - Universidade de Brasília, Brasília, 2016.

MAFRA, G.; BARROS, E. Revisão coletiva, correção do professor e autoavaliação: atividades mediadoras da aprendizagem da escrita. Diálogo das Letras, Pau dos Ferros, v. 6, n. 1, p. 33-62, jan./jun. 2017.

MARCUSCHI, L. A. Da fala para a escrita: atividades de retextualização. São Paulo: Cortez, 2000.

MARCUSCHI, L. A. Produção textual, análise de gêneros e compreensão. São Paulo: Parábola, 2009.

MIRANDA, A.; FERRAZ, M. A produção textual sob a perspectiva do ISD: a reescrita em foco. Eutomia, Recife, v. 14, n. 1, p. 144-166, dez. 2014.

MORONI, A.; GOMES, J. A. O Português como Língua de Herança hoje e o trabalho da Associação de Pais de Brasileirinhos na Catalunha. Revista de Estudios Brasileños, v. 2, n. 2, p. 21-35, jan./jun. 2015.

MOUTINHO, R.; ALMEIDA FILHO, J. C. P. The role of language teachers as cultural diplomats. Multicultural Education Review, v. 7, n. 1-2, p. 85-98, 2015. 
NYE, J. S. Born to lead. The changing nature of American Power. Nova York: Basic Books, 1990.

PACHECO, D. G. L. da C. Português para estrangeiros e os materiais didáticos: um olhar discursivo. 2006. Tese (Doutorado em Letras Vernáculas) - Universidade Federal do Rio de Janeiro, Rio de Janeiro, 2006.

RAJAGOPALAN, K. Política de ensino de línguas no Brasil: história e reflexões prospectivas. In: MOITA LOPES, L. P. (org.). Linguística aplicada na modernidade recente: Festschrift para Antonieta. São Paulo: Parábola, 2013. p. 143-161.

SCHULTZ, R. A. The challenge of assessing cultural understanding in the context of foreign language instruction. Foreign Language Annals, v. 40, n. 1, p. 9-26, Mar. 2007.

SILVA, A. L.; SIMÃO, A. M.; SÁ, I. A auto-regulação da aprendizagem: estudos teóricos e empíricos. Intermeio: Revista do Mestrado em Educação, Campo Grande, MS, v. 10, n. 19, p. 58-74, 2004.

SOARES, M. As pesquisas nas áreas específicas influenciando o curso de formação de professores de $1^{\circ} \mathrm{e}$ $2^{\text {o }}$ graus. Linha d'Água, v. 13, p. 33-44, jun. 1998.

SOUZA, A; BARRADAS, O. Português como língua de herança: políticas linguísticas na Inglaterra. Revista SIPLE, v. 4, n. 1, 2013. Disponível em: https://bit.ly/36WQo2N. Acesso em: 03 abr. 2020.

SU, Y. C. The effects of the cultural portfolio project on cultural and EFL learning in Taiwan's EFL college classes. Language Teaching Research, v. 15, n. 2, p. 230-252, Apr. 2011.

TRAVAGLIA, Luiz Carlos et al. Gêneros orais - conceituação e caracterização. In: SIMPÓSIO NACIONAL DE LETRAS E LINGUÍSTICA, 14., SIMPÓSIO INTERNACIONAL DE LETRAS E LINGUÍSTICA, 4., 2013, Uberlândia. Anais do SILEL, v. 3, n 1. Uberlândia: EDUFU, 2013. p. 1-8.

TRIPP, D. Pesquisa-ação: uma introdução metodológica. Educação e Pesquisa, São Paulo, v. 31, n. 3, p. 443466, set./dez. 2005. Tradução Lólio Lourenço de Oliveira.

TROUCHE, L. M. Gêneros textuais, polifonia e competência comunicativa no ensino de PLE. In: ENCONTRO PLE 2007 PUC/RJ, 2007, Rio de Janeiro. Rio de Janeiro: PUC-Rio, 2007. (Comunicação em Mesa-Redonda). Disponível em: http://bit.ly/38kBpiN. Acesso em: 08 abr. 2020.

VIANA, N. Planejamento de cursos de línguas - pressupostos e percurso. In: ALMEIDA FILHO, J. C. P. de. (org.). Parâmetros atuais para o ensino de Português Lingua Estrangeira. Campinas: Pontes, 1997. p. 29-48.

VILLAÇA, M. L. Métodos de ensino de línguas estrangeiras: fundamentos, críticas e ecletismo. Revista Eletrônica do Instituto de Humanidades, v. 7, n. 26, p. 73-88, jul./set. 2008.

WANG, J. Introduction: China's search of soft power. In: WANG, J. (ed.). Soft power in China: Public diplomacy through communication. Nova York: Palgrave MacMillan, 2011. p. 1-18.

YAMAMOTO, M. Considerações sobre o ensino de PLE em contexto de ensino superior. Domínios de Lingu@gem, v. 8, n. 1, p. 485-501, jun. 2014. 